\title{
Breaking Out of the Local: International dimensions of science shops
}

\author{
CAspar DEBok AND NORBERT StEINHAUS
}

W hat is the air quality like, right here, at my front door, downtown in this big city? This question has been put many times in recent years to Science Shops. There is a growing concern among citizens on local air quality and the impact it is having on their health. City traffic is becoming more and more dense, traffic jams are on the rise and rush hours last longer. There is more traffic and more pollution from cars. In 2006 the European Environment Agency (EEA) published a report on air pollution at street level in European cities (EEA 2006). The EEA concludes that traffic-related air pollution is still one of the most pressing problems in urban areas. Human exposure to increased concentrations of pollutants, especially the so-called fine particles, in densely populated urban areas is high. Air quality controls, which are aimed at protecting public health, are frequently exceeded, especially in streets and other urban hotspots.

More generally, Science Shops, as well as regional and local Civil Society Organisations (CSOs), have been confronted with an

Gateways: International Journal of Community Research and Engagement No 1 (2008): 165-178

(C) UTSePress and the authors 
increasing number of requests from citizens on local environmental issues. Many of these requests focus on the lack of information that is available for citizens. The Aarhus Convention, signed by many countries of the United Nations in 1998 and brought into force in 2001, obliges local governments to inform citizens about local environmental conditions and to create opportunities for citizens to participate in (environmental) decision-making processes at the local level. Science Shops and CSOs or NGOs get many requests for support from citizens on how to access available information, how to assess this information and how to participate in local decisionmaking processes.

Since 2005 the Science Shop for Biology at Utrecht University (since January 1, 2008, the Science Shop of the Faculty of Science) has initiated several projects on local air quality, often in close cooperation with the Interfaculty Institute of Risk Assessment Sciences at Utrecht University and several community organisations. In cooperation with a local CSO, the Science Shop developed guidelines and a pilot version for an information tool on local air quality for citizens. In cooperation with the Dutch Cyclists' Union they initiated a real-time research project to measure exposure (of cyclists) to fine particles and ultra-fine particles. This research was the basis for a national discussion in early 2008 on air pollution by mopeds compared to cars.

\section{CiTIZENS AND SCIENCE SHOPS}

Science Shops are not 'shops' in the traditional sense of the word. They are often, but not always, linked to universities, where students conduct the research as part of their curriculum. Most Science Shops are small entities that carry out scientific research in a wide range of disciplines usually free of charge and on behalf of citizens and local civil society. In the Netherlands as well as in other countries, requests are not only directed to Science Shops but also to several local environmental organizations. These requests come from many individuals who are often not aware of other individuals that are raising the same questions. In fact, those individual questions are of general interest and are not individual at all. For example, the fact that many individuals and local environmental organizations and even regional umbrella organizations contact the Science Shops clearly show that there is broad concern about local air quality. And although some general information on local air quality is available, 
citizens or small organisations are often not aware of it. The problem is that they lack access to this information in a practical way. And when they do have access to the information they often do not have the expertise to assess it.

The many requests Science Shops receive clearly show that providing information on its own isn't sufficient to raise citizens understanding of scientific information. Awareness and understanding of scientific information and knowledge will be an essential step towards greater public participation in decision-making processes. Thus additional efforts are needed to really bridge the gap between science and society. The Interacts case studies (Jørgensen et al. 2004) show that when NGOs or citizens approach Science Shops, their need for knowledge can be categorized in terms of:

- Scientific analysis of a problem;

- Enhancement of knowledge around a certain topic;

- Research on the impact of governmental projects;

- Development of solutions;

- Evaluation of NGO or community services/projects.

Getting access to free or low cost research and independent research through the Science Shops is an important instrument that helps NGOs and local communities to participate in decision-making procedures.

The fact that Science Shops respond to civil society's needs for expertise and knowledge is a key element that distinguishes them from other mechanisms of knowledge transfer. Nowadays, a straightforward publication of scientific results and one-way science communication will not suffice. But there is a change going on.

\section{A BRIEF THEORETICAL BACKGROUND ON SCIENCE AND SOCIETY RELATIONS}

The relation between science and society is changing. Nowotny, Scott and Gibbons (2000) clearly describe an improved interaction in knowledge transfer. For a long period science and society have been separate entities, with hardly any exchange (Mode-1 science - Mode1 society). Often this has been referred to as science placing itself in an ivory tower. Nowadays science and society are approaching each other. It started with a growing interest in societal applications of 
science, guided by science. It was still a rather one-way operation (mode-2 Science). More recent is the growing interest of society in the applications of science, with society becoming the demanding party (mode-2 society). Science and society relations seem to be changing to a more two-way modus of knowledge transfer, getting closer to what can be called a real dialogue.

It is fair to ask, however, if there is a real two-way communication on knowledge transfer occurring. European citizens, at least, do have an ambiguous relation to science. In 2005 the European Commission (EC), published a new Eurobarometer report (EC 2005a), which was a survey on the perception of European citizens regarding science and technology. On the one hand European citizens do not feel well informed about innovations and developments in science and technology but on the other hand they lack interest. There seems to be a strong confidence in science and technology. For real confidence, however, there is a need to understand. Do citizens understand the implications of new developments in science and technology, or do they trust the sender of this information? Much of the communication about science still relies on a rather traditional sender-receiver means of communication. Since the late twentieth century many reports and articles about the good results to be gained from a real two-way and interactive science communication (for example, see Felt 2003) have been published, which underline the increasing awareness of the importance of dialogue.

The European Commission supported the many voices that discussed the need for a more society-based impact assessment that could exist alongside the traditional assessments systems of scientific research. Universities are key players in the process to strengthen the role of community involvement in the evaluation of scientific research (EC 2005b).

\section{SCIENCE AND SOCIETY IN THE EUROPEAN UNION}

In 2000 the European Union adopted the Lisbon Agenda (EU 2000), whose aims are to make Europe by 2010 the world's most competitive and dynamic knowledge-based economy, with sustainable growth, more and better jobs and greater social cohesion. Europe should be a real knowledge society. As one of the instruments to achieve the Lisbon targets the European Commission in 2001 launched the Science and Society Programme. With this programme, 
established in the Research Directorate General (DG Research), the EC intends to bridge the gap between the scientific community and society at large by creating better interaction between science and society. The past European Framework for Research (the Sixth Framework Programme for Research (FP6), 2002-2006) focused on twelve main research topics. Besides these research topics other themes were linked to all of the research themes, in so called horizontal programmes. As one of the horizontal programmes the Science and Society Programme supported activities that brought together policy-makers, researchers and citizens from all the thematic research fields. Within the frame of this programme, support has also been given to the Science Shops.

The Science Shops were really first catapulted into the European public eye by the EC, which established the 'Science and Society Action Plan' in 2001 (EC 2002). At the centre of this was a dialogue between citizens and scientists, and the intention 'to pool efforts at the European level to develop stronger and more harmonious relations between science and society.' The Commission's support was just as strong for the mediators acting between citizens and science, namely the Science Shops and similar institutions.

In November 2005 the EC published a Science Shop call for proposals as part of the Science and Society Programme. The general objective of the call was to contribute to the universities' aim of sharing knowledge with society - in particular in the context of regional and local development - by supporting the development and strengthening of Science Shops (and similar organizations) based in, or cooperating with, universities. The call aimed to support Science Shops in addressing the specific needs identified by local civil society, while at the same time optimizing the use of available research results and expertise.

Emphasizing the local dimension of the research while simultaneously fostering international cooperation with organizations dealing with the same kind of local research questions (such as, for example, the issue of local air quality) were the key elements of this EC call. The call was a big success with twenty seven high-quality proposals qualifying for funding. Unfortunately the budget was too limited and only four projects received funding.

On 18 December 2006, the Seventh Framework Programme for Research and Technological Development (FP7) of the European 
Community (EC) for the period 2007-2013 was adopted. This new framework programme clearly shows Europe's vision on research and the future role of Europe in science and of science in Europe. The scope of this article doesn't allow us to go into details of FP7, but relevant information about Europe's new research policy can be found at the FP7 website. ${ }^{1}$

Europe's research policy is changing and of course the new vision has been heavily discussed and negotiated with the very many stakeholders, from multinationals to research institutes. On a smaller scale representatives of NGOs and citizens' organisations have been involved as well, for example, at the Science and Society Forum. At this forum there was a clear voice to open up Europe's research funding structures and instruments to small NGOs and citizens' representatives (EC 2005c).

In the Science and Society FP7 work programmes (EC 2007) each year several calls for proposals are announced, which are of interest to Science Shops. Although the pilot call in FP6 was a success, there has not been another call specific to Science Shops but there are clearly relevant elements for Science Shop like activities in the Science and Society calls in 2007 and 2008.

\section{KNOWLEDGE SOCIETY}

In the future major changes in Europe's research policy will take place due to a revised selection of research themes and processes for project funding and research cooperation. Although there have been thematic shifts in the new European research strategy for 2007-2013, the Science and Society programme will be strengthened. In FP7 the Science and Society programme will be part of the Directorate Science, Economy and Society. It is not yet clear how this will be worked out in the yearly work programmes of the EC. However, there is a general tendency (not only at the EC) to reduce knowledgesociety to knowledge-economy. Now, when talking about innovation in relation to research, mainly technological innovation is mentioned. Social innovation is often not included in this context. On the other hand there is a growing understanding that this is a limited and short-term approach only. To achieve a real knowledge society in the long term, there is a need for a broad understanding of what a knowledge society is.

\footnotetext{
${ }^{1}$ See http: / / ec.europa.eu/research/fp7/home_en.html.
} 
'In a knowledge society that aims to be more than a knowledge economy, Science Shops have a special place,' explains Maria van der Hoeven, Dutch former Minister of Education, Culture and Science. The Dutch minister (nowadays of Economic Affairs) is a particular admirer of the 'unique bottom-up approach' of Science Shops.

'By supporting citizens in their quest for knowledge, people are given more possibilities to take responsibility for shaping their own life and their living environment,' she says. In the Netherlands she urged the universities to take into account the economic and non-economic (or indirect economic) aspects of knowledge society (EC 2003).

\section{SCIENCE SHOPS: FROM 1970 TO 2008}

In the early 1970s the student movement had a strong focus on the democratization of universities in Europe. Universities had to come down from their ivory towers where theoretical and monodisciplinary knowledge prevailed. At that time there was no direct link to daily problems in society, where some of the side effects of technological development were becoming visible. Universities had to increase the role of society in research and to foster contacts between the public and science and scientists.

In the Netherlands this led to an increasing demand for applied research and education in academic curricula. Some critical university staff as well as students joined forces to help civil society groups increase their knowledge. They introduced project education in university settings as an addition to regular lecture-based classes. Their efforts coincided with a growing environmental awareness and the development of civil society organizations. On the waves of this movement Science Shops emerged (directly translating this forms the Dutch word for these organizations: Wetenschapswinkels, where wetenschap means science, and winkels means shops). The Dutch word for science has, to a lesser extent than in English, a bias on the natural sciences. However, the word 'science' in the name Science Shop is used in its broadest sense, so it includes the social sciences, natural sciences, the humanities and engineering.

The Dutch Science Shops were grounded on the idea that universities had to play a more prominent role in the solution of social and environmental problems. Within universities Science Shops started to build partnerships with civil society. By the end of the 1970s, almost all Dutch universities had a Science Shop in which 
staff worked on research requests from civil society groups. Science Shops became recognized intermediaries between science (the universities) and society, working in an open way and orientated towards interaction (Farkas 2002).

Nowadays, Science Shops have consolidated their bridging function between universities and society. Organizations can apply for research assignments in all areas of science such as nature, environment, health, art and culture, law, social work and communication. Science Shops offer students the opportunity to do community-based research and enable community groups to get access to university research resources, or support in scientific methodology or processes. From a modest extension of a university service on a voluntary basis, their number has today mushroomed to more than thirty professional organizations in the Netherlands, while also spreading to several countries across the world (such as Videnskapsbutikken in Denmark, Wissenschaftsladen in Germany and Austria, Intermediu in Romania, Science Shop in the UK, Community Based Research Center in the USA) and Shopfront, at the University of Technology Sydney, celebrated its tenth anniversary in 2006.

There is not one standard model for Science Shops because they function within different socio-political, cultural and organizational contexts (Mulder et al. 2001). There are, however, some important parallels among the many different types of Science Shops. By focusing on these parallels an international group of organizations identified themselves as Science Shops, with the following definition:

A Science Shop provides independent, participatory research support in response to concerns experienced by civil society.

Science Shops appear all over the world but operate in many different ways. What they have in common is their demand-driven and bottom-up approach. They also share an interactive dialogue with community and community involvement in research (Mulder and De Bok 2006). A participant of the 2006 Science Shop summer school, an activity in the EC-funded Science Shop project TRAMS (see below), compared the Science Shops with goulash soup. The taste is different depending on where you cook it but the ingredients are similar. 
Indeed there are many differences in the way Science Shops meet the above definition but they all have a general mission statement in common. They all seek to:

- provide civil society with knowledge and skills through research and education;

- provide their services on an affordable basis;

- promote and support public access to and influence on science and technology;

- create equitable and supportive partnerships with civil society organizations;

- enhance understanding among policymakers as well as education and research institutions of the research and education needs of civil society;

- enhance the transferable skills and knowledge of students, community representatives and researchers.

In practice, Science Shop work starts with a first contact between a civil society organization and a Science Shop on a specific problem. Then in a cooperative search for a solution new knowledge is generated, or at least existing knowledge is combined and adapted in a true partnership without 'science' prevailing in any way. Through their contacts, however, Science Shops also provide a unique 'antenna function' of society's current and future demands on science (Hende and Jørgensen 2001).

In France and Belgium, the 'Science and Society Action Plan' of the EC (EC 2002), mentioned earlier, led to a revival of the Science Shop concept, while in Spain the very first Science Shops came into being for the first time. In Germany and Switzerland, as well, several initiatives have since got under way.

With the financial support of the EC, some of the European Science Shops have managed to organise themselves into a European (or even global) network called Living Knowledge. Online information, training material, empirical reports, meetings and conferences have been developed or organised. Above all, however, the network is an aid for those who wish to open up a Science Shop. They can inform themselves of the various forms of Science Shop and choose the one that would suit them best. 
Some of the more recent Science Shop like initiatives are the merging of Italian Science Shops in 2006, the start of the first Science Shops in Hungary (summer 2006), Glamorgan (Wales) and China (Shanghai) in November 2006 and new activities in Cork (Ireland) and Lisbon (Portugal). And, of course, the start of the Office of Community Based Research at the University of Victoria (BC, Canada) in 2007. And some students have come knocking again: from Greece, Turkey and Iceland, as well as from the new EU-member states in Eastern Europe.

And yet these actors of the 'new generation' differ from those of the founding generation: they tend to be more heterogeneous regarding their organizational structure as well as their fields of work, orientating themselves to community-based research, an approach which allows those carrying out the research and those requesting information to work much more closely together. They also profit from the experiences of scientists and citizens gained from using numerous new forms of dialogue and participation.

The 3rd Living Knowledge Conference in Paris (August 2007) offered a unique platform for the different concepts of Science Shops and like organisations to be discussed.

\section{TRAMS}

In recent years, established Science Shops have been increasingly asked to support the development of structures, procedures and materials for organisations that were about to start a Science Shop. Many ad hoc initiatives worked to fulfil the needs of (new) Science Shops. It was clear there was a growing need for more systematic efforts to share experiences and good practices. However, the Science Shop concept couldn't be simply copied but needed to be adapted to the local contexts of the new organizations. Local citizens' needs and demands for research supply and mediation structures, host organisations and research funding structures are just some of the factors that are of relevance for the success or failure of a new Science Shop initiative.

To structure and support new Science Shop initiatives a threeyear EU-funded project 'Training and Mentoring of Science Shops' (TRAMS) started in May 2005. TRAMS will offer a toolbox with training materials for new and existing Science Shops. It will offer them the opportunity to get started or to increase professionalism. Besides a toolbox TRAMS will offer new Science Shops a tailor-made 
mentoring programme for practical advice and support. TRAMS will focus on:

- a mentoring programme for Science Shops;

- training materials and programmes;

- e-modules and e-learning tools;

- dissemination of training and mentoring activities.

In TRAMS eighteen organizations from fourteen countries (Austria, Belgium, Denmark, Estonia, France, Germany, Greece, Iceland, Latvia, Netherlands, Romania, United Kingdom, Spain and Turkey) cooperate. TRAMS is a joint effort of experienced and new Science Shops. This combination of users (new Science Shop initiatives) and suppliers (experienced Science Shops) will be a guarantee of customized tools and a relevant content for the toolbox. TRAMS will run pilot projects with the intention of offering structural services for the international Science Shop network Living Knowledge.

One of the spin offs of TRAMS that may become a structural service was the Science Shop summer school. In August 2006 thirty two participants from all over the world participated in this threeday course on Science Shops. Experienced Science Shop staff discussed operational options and good practices, but also barriers to running a Science Shop. Examples of different Science Shop models were presented and site visits to different types of Science Shops in the Netherlands have been organized. At the 3rd Living Knowledge Conference in Paris (2007) and the Community-University Exposition (CUexpo 2008) at the University of Victoria (BC, Canada) this course has been offered in different, shorter formats.

Because Living Knowledge is an open network, the deliverables of TRAMS - for example, a guide for Scenario Workshops (Gnaiger and Schroffenegger 2008) and a FAQ-section and Science Shop toolbox on the Living Knowledge website ${ }^{2}$ are available for all organisations that are interested in community-based research and the concept of Science Shops. The free Living Knowledge newsletter and the discussion group are the main communication tools for sharing community-based research experiences around the world.

\footnotetext{
${ }^{2}$ See www.livingknowledge.org.
} 


\section{FUtURE DiRECTIONS AND CHALLENGES}

In the last ten years Science Shops have come back on the agenda of science policy-making. But they also seem to be at a crossroads, where their work focus and their coalitions may have to change. On the one hand, they are still connected to their roots, the social movements. On the other hand, a general trend towards business cooperation in science policy can be observed. In this new context Science Shops face the challenge of positioning themselves between these two trends (Fischer et al. 2004). In addition, resources have to be built up to maintain active cooperation on an international level and to allow Science Shops to work in a network, but still remain in close cooperation with their citizens.

In this context the 3rd Living Knowledge Conference, held in Paris in August 2007 and titled 'Communities building knowledge Innovation through citizens' science and university engagement' was already a great success (Steinhaus 2008). More than 330 people from over fifty countries joined one or more of the eighteen sessions; the number and the quality of the presentations revealed the expertise and competence of the associations and social movements in the scientific domain. So it's time that civil society be recognized as a producer of knowledge, and that this 'third scientific sector' be accepted as a partner in public research directed towards public interest. There is an ongoing interest in and attention given to the participation of citizens in community-based research in sciencebased policy processes and decision-making procedures. However, there is still a long way to go before citizens will be fully accepted as equal partners and providers of knowledge and expertise.

One of the most important outcomes of the conference therefore was the strong wish for global networking. Many participants expressed their willingness to help with the next steps in building global connections in community-based research. This is also a question of marketing and lobbying. We now have to think about how to combine our network capacities and how to link initiatives around the world. At the CUexpo 2008 a first step was made by the introduction of GACER, the Global Alliance on Community-Engaged Research (see www.livingknowledge.org). With GACER, the representatives of the Community Based and Participatory Action Networks present at CUexpo 2008 declared that the right to learn, the right to know, the right to produce knowledge, and the right to access knowledge are inalienable rights for all. 
The alternating CUexpo and Living Knowledge conferences offer a good international forum to share experiences, but there is a need to build on this in a way that really brings into practice the ideas of GACER with hands-on activities. We hope to meet many of you to share experiences and build active partnerships (before and) at the 4th Living Knowledge Conference, in Belfast, August 2009.

\section{REFERENCES}

EC, 2007, Workprogramme 2007. Capacities, Part 5. Science in Society., C(2007)563 of 26.02.2007.

EC, 2005a, Special Eurobarometer 224: Europeans, science and technology., ECDG Research. EB63.1

EC, 2005b, European Universities: Enhancing Europe's Research Base. Report by the Forum on University-based Research, ISBN 92-894-9307-0.

EC, 2005c, Questions of science - Echos from the Science in Society Forum, KI-6905-359-EN-C, ISBN 92-894-9939-7.

EC, 2003, Science Shops: knowledge for the community, EUR 20877, ISBN 91-8946246-9.

EC, 2002, Science and Society - Action Plan, ISBN 92-894-3025-7.

EEA, 2006, Air pollution at street level in European cities, EEA Technical report No 1/2006, ISBN 92-9167-815-5.

EU, 2000, Presidency conclusions. Lisbon European Council, 23 and 24 March 2000.

Farkas, N 2002, Bread, cheese, and expertise - Dutch Science Shops and democratic institutions, unpublished Ph.D. Thesis, Rensselaer Polytechnic Institute, Troy NY, USA.

Felt, U (ed.), 2003, O.P.U.S. - Optimising Public Understanding of Science and Technology, Final report, University of Vienna.

Fischer, C; Leydesdorff, L; Schophaus, M: $\underline{\text { science Shops in Europe: The }}$ Public as Stakeholder (2004), Science \& Public Policy, 31(3), 2004, 199-211.

Gnaiger, A \& Schroffenegger, G 2008, Toolkit Scenario Workshop, TRAMS Training and Mentoring of Science Shops, The FBI Centre, Innsbruck, Austria. 
Gateways | De Bok \& Steinhaus

Hende, M \& Jørgensen, M S 2001, The Impact of Science Shops on University Curricula and Research, SCIPAS Report No. 6, Utrecht University.

Jørgensen, MS, Hall, I, Hall, D, Gnaiger, A, Schroffenegger, G, Brodersen, S, von der Heiden, K, Reimer, R, Strähle, M, Urban, C, Endler, W, Teodosiu, C, Rojo, T \& Leydesdorff, L 2004, Democratic Governance through Interaction between NGO's, Universities and Science Shops: Experiences, Expectations, Recommendations. Final report of Interacts, ISBN 87-91035-26-0.

Mulder, H \& De Bok, C 2006, 'Science Shops as university-community interfaces: An interactive approach in science communication', in D Cheng, J Metcalfe \& B Schiele (eds), At the human scale: International practices in science communication, Science Press, Beijing.

Mulder, H, Auf Der Heyde, T, Goffer, R \& Teodosiu, C 2001, Success and Failure in Starting Science Shops, SCIPAS Report No. 2, Utrecht University.

Nowotny, H, Scott, P \& Gibbons, P 2001, Re-thinking science: Knowledge and the public in an age of uncertainty, Policy Press, Cambridge.

Steinhaus, N (ed.) 2008, Proceedings of the 3rd Living Knowledge Conference, Paris 2007: Communities Building Knowledge: Innovations through Citizens' Science and University Engagement. DVD available for free via editor. 